BMJ Open Sport \& Exercise Medicine

\title{
Retrospective study of the use of medication and supplements during the 2018 FIFA World Cup Russia
}

\author{
Chelsea Oester, ${ }^{\circledR}$ Alexis Weber, Martin Vaso
}

To cite: Oester C, Weber A, Vaso M. Retrospective study of the use of medication and supplements during the 2018 FIFA World Cup Russia. BMJ Open Sport \& Exercise Medicine 2019;5:e000609. doi:10.1136/ bmjsem-2019-000609

Accepted 28 July 2019
Check for updates

\section{(C) Author(s) (or their} employer(s)) 2019. Re-use permitted under CC BY-NC. No commercial re-use. See rights and permissions. Published by BMJ

Fédération Internationale de Football Association, Zurich, Switzerland

Correspondence to Chelsea Oester; chelsea.oester@fifa.org

\section{ABSTRACT}

Objective Examine the intake of medication and supplements used by top-level players during the 2018 FIFA World Cup Russia.

Participants 736 top-level players

Setting The team doctors uploaded a list of the medications used by each player to the online reporting tool within 72 hours of each match of the 2018 FIFA World Cup Russia.

Outcome measures Average number of medications used per player per match and during the tournament; average number and percentage of players using at least one medication per match and during the tournament. Results $54 \%$ of the players took at least one medication during the tournament and $39 \%$ took at least one medication before each match. The most used medications were non-steroidal anti-inflammatory drug (NSAID) $(38.6 \%)$, followed by other analgesics (13.8\%) and medications for insomnia and anxiety (13\%). On average, 0.72 medications were taken per player per match and 1.32 per player during the tournament. The mean number of medication intake per player per match was higher during the knockout stage compared with the group stage $(0.88 \pm 1.36$ vs $0.65 \pm 1.08, p<0.001)$. Players from South America and North and Central America took more medications per match compared with the players from Africa $(0.9 \pm 1.14$ and $0.98 \pm 1.1$ vs $0.48 \pm 0.83, p<0.001$ in both cases).

Conclusion The intake of NSAIDs decreased during the 2018 FIFA World Cup compared with previous FIFA World Cups, but stayed at a high level. The high number of medications taken is a cause for concern, and therefore, players, medical staff and coaches should be made more aware of the possible side effects of a high medication intake.

\section{INTRODUCTION}

The use of medication and supplements is widespread in professional sport. Several studies have shown that the high use of medication by elite athletes is a concern, as it can have negative effects on their health. ${ }^{1-7}$ FIFA has been analysing the medication intake of players during the World Cup since 1998. Other research groups have also looked into the medication intake of elite athletes and have reported that the latter use more
Summary

Aims
To analyse the medication and supplement intake of
top-level football players during the 2018 FIFA World
Cup and to compare it with those of previous FIFA
World Cups.

Key messages

- The intake of non-steroidal anti-inflammatory drugs during the 2018 FIFA World Cup Russia remained at a high level.

- The results found were similar to those from previous FIFA World Cups.

- Players, medical staff and coaches should be made more aware of the side effects of a high medication and supplement intake.

Strengths and limitations of this study

- This study shows the medication intake of top-level football players.

- It compares the medication and supplement intake with previous FIFA World Cups and studies whether there is a need to increase the awareness of all actors involved in football about the side effects of particular medications.

- As the study relies on information provided by the team doctors, data might be incomplete.

medications compared with age-matched control groups and that the medication intake is significantly higher in team sports compared with individual events. ${ }^{89}$ Despite a trend towards a decrease of non-steroidal anti-inflammatory drug (NSAID) intake per match seen during the previous World Cups, the average number of NSAIDs used per player remained at a high level. ${ }^{3410}$ Reasons for the high intake of analgesics, NSAIDs and other medications could be the demands of the sport, prophylactic pain treatment, a lack of knowledge of the possible negative effects and the ability of injured players to resume playing before they have fully recovered. ${ }^{2}$

The aim of this study was to compare the use of medication and supplements during the 2018 FIFA World Cup with that of 
previous World Cups, as one of FIFA's aims is to educate the players about the possible adverse effects of a high intake of medication and supplements.

\section{METHODS}

During the 2018 FIFA World Cup, the team doctors had to share details of all medications taken by the players 72 hours preceding the match, submitting this information for the first time with the help of an online reporting tool. The definition of substance groups remained the same as the one used previously, namely, NSAIDs, analgesics, injected glucocorticosteroids and local anaesthetics, muscle relaxants, respiratory drugs, medication for gastrointestinal and antimicrobial purposes, psychotropic substances, other medications and supplements. In line with previous studies conducted by FIFA, paracetamol and metamizole were counted as analgesics. All supplements taken by a player prior to a match were counted as one supplement regardless of the number of substances involved.

For the 2018 FIFA World Cup, 32 countries qualified, each with a squad of 23 players, which gave a total of 736 players participating at the tournament. Sixty-four matches were played, resulting in 2944 data sets of medication intake. The group stage featured 48 matches and the knockout stage 16 . The minimum number of matches a team could play was three and the maximum was seven.

\section{Data presentation and statistical analysis}

The results were presented as follows: (1) average number of medications taken per player per match or during the tournament and (2) average percentage of players using at least one medication per match or during the tournament.

The statistical methods applied were frequencies and means, presented with $\mathrm{SD}, 95 \%$ CIs and unpaired t-tests. The significance level was $p \leq 0.05$.

\section{RESULTS}

A total of 2123 medications and 1311 supplements were reported to be taken by players in the 2018 FIFA World Cup (see table 1). NSAIDs were the medication most taken $(38.6 \%, \mathrm{n}=820)$, and diclofenac was the most frequently prescribed NSAID $(49.1 \%, \mathrm{n}=403)$, followed by etoricoxib $(14.1 \%, \mathrm{n}=116)$ and celecoxib $(14 \%, \mathrm{n}=115)$. The other pain-related medication groups were 'other analgesics' $(13.8 \%, \mathrm{n}=292)$, with paracetamol being the analgesic most often taken $(88.4 \%, \mathrm{n}=258)$, and 'muscle relaxants' $(6.7 \%, \mathrm{n}=143)$. Other medications prescribed were injections $(1.3 \%, \mathrm{n}=27)$, whereas glucose injections counted for $74 \%$ of all injections $(n=20), \beta-2$ agonists $(0.9 \% ; \mathrm{n}=20)$, medications for insomnia and anxiety $(13 \%, \mathrm{n}=277)$, respiratory medications without antihistamines and $\beta$-2 agonists $(7.1 \%, \mathrm{n}=150)$, and antimicrobial agents $(2.4 \%, n=51)$. Five players used a $\beta-2$ agonist, all of them inhaling salbutamol $(n=20)$.

Table 1 Use of medication in the 2018 FIFA World Cup

\begin{tabular}{|c|c|c|c|c|c|}
\hline & \multirow{2}{*}{$\begin{array}{l}\text { Total } \\
\text { number of } \\
\text { medications }\end{array}$} & \multicolumn{2}{|c|}{$\begin{array}{l}\text { Average number of medications } \\
\text { used per player }(m e a n \pm S D)\end{array}$} & \multicolumn{2}{|c|}{ Players using a medication } \\
\hline & & Per match & $\begin{array}{l}2018 \text { FIFA World } \\
\text { Cup }\end{array}$ & Per match (\%) & $\begin{array}{l}2018 \text { FIFA World Cup } \\
\text { (\%) }\end{array}$ \\
\hline Any medication & 2123 & $0.72 \pm 1.17$ & $1.32 \pm 1.65$ & 39 & 54 \\
\hline NSAIDs & 820 & $0.28 \pm 0.52$ & $0.52 \pm 0.7$ & 24 & 40 \\
\hline Injections* & 27 & $0.01 \pm 0.1$ & $0.02 \pm 0.18$ & 1 & 2 \\
\hline Analgesics & 292 & $0.1 \pm 0.31$ & $0.19 \pm 0.42$ & 10 & 17 \\
\hline$\beta-2$ agonists & 20 & $0.01 \pm 0.08$ & $0.01 \pm 0.08$ & 1 & 1 \\
\hline Antihistamines & 103 & $0.03 \pm 0.21$ & $0.06 \pm 0.27$ & 3 & 5 \\
\hline Other & 861 & $0.29 \pm 0.67$ & $0.49 \pm 0.92$ & 29 & 53 \\
\hline \multicolumn{6}{|l|}{ By stage } \\
\hline Group & 1470 & $0.65 \pm 1.08$ & & 32 & \\
\hline Knockout & 653 & $0.88 \pm 1.36$ & & 47 & \\
\hline \multicolumn{6}{|c|}{ By confederation } \\
\hline AFC & 297 & $0.81 \pm 1.31$ & $1.39 \pm 1.2$ & 35 & 47 \\
\hline CAF & 166 & $0.48 \pm 0.83$ & $0.88 \pm 0.45$ & 32 & 46 \\
\hline UEFA & 998 & $0.66 \pm 1.19$ & $1.17 \pm 1.17$ & 35 & 49 \\
\hline Concacaf & 226 & $0.98 \pm 1.1$ & $1.83 \pm 1.01$ & 53 & 74 \\
\hline CONMEBOL & 436 & $0.9 \pm 1.14$ & $1.84 \pm 0.47$ & 51 & 77 \\
\hline
\end{tabular}

${ }^{*}$ Of glucocorticosteroids and local anaesthetics.

AFC, Asian Football Confederation; CAF, Confederation of African Football; CONMEBOL, South American Football Confederation; Concacaf, Confederation of North, Central American and Caribbean Association Football; NSAIDs, non-steroidal anti-inflammatory drugs. 
On average, $54 \%$ of the players took at least one type of medication during the tournament, and $39 \%$ did so before each match regardless of whether they participated in the match (see table 1). The average number of medications declared was 0.72 per player per match and 1.32 per player during the tournament. Considerable differences were found between teams. In two of them, each player took medication during the tournament, with an average of 2.96 different medications per player for one team and 4.65 for the other. The maximum average number of prescribed medications found in all teams was 4.65 medications per player, while there were a minimum of 0.13 medications per player in a team during the tournament. Two players were reported to have taken a total of 12 different medications during the entire tournament. For the team with the lowest medication intake, only one player consumed medication during the entire tournament ( $4 \%, \mathrm{n}=1$ player).

The average number of medications per player and per match ranged from 0.11 to 2.13, while the NSAID intake varied from 0.04 to 0.61 NSAIDs per player and per match. One player took nine different medications in the 72 hours leading up to a single match. Furthermore, one player took three different NSAIDs in the 72 hours prior to a match. In one team, the same medication (analgesic) and a supplement were prescribed to every player in the 72 hours prior to the match. For three other teams, all players took the same supplement in the 72 hours prior to the match.

In the group stage, fewer players took at least one medication per match than in the knockout stage $(32 \%$ vs $47 \%$; see table 1). A similar increase from the group stage to the knockout stage was found for the mean number of all medications per player and per match (see table $1 ; \mathrm{p}<0.001$ ), as well as the mean number of NSAIDs per player and per match $(0.26,95 \%$ CI 0.24 to 0.28 , vs $0.32,95 \%$ CI 0.28 to 0.36$)$.

When looking at regional patterns, the teams from South and Central America had the highest reported use of medications per player per match and during the entire tournament compared with the other regions (see table 1). The average intake per player per match was significantly higher for those two regions compared with the European and African countries $(p<0.001)$. The difference was not significant when compared with the Asian countries (see table 1).

Half of the players participating at the 2018 World Cup were born before September 1990, and the other half were born after that month. Among players taking medication, the average number of medications was higher in older players, that is, those born before September 1990, compared with younger players $(1.59,95 \%$ CI 1.4 to 1.78 , vs $1.05,95 \%$ CI 0.91 to 1.19 ). The NSAID intake was also higher for the older players compared with the younger players $(0.61,95 \%$ CI 0.54 to 0.69 , vs $0.42,95 \%$ CI 0.35 to 0.49 ). When taking the same age groups as 4 years ago, the average number of medications was higher in older players born between 1973 and 1985 (average of
1.6 medications per player, $\mathrm{n}=97,95 \%$ CI 1.28 to 1.92 ) compared with younger players born between 1986 and 1994 (average of 1.35 medications per player, $n=534,95 \%$ CI 1.21 to 1.49) and between 1995 and 1999 (average of 0.9 medications per player, $\mathrm{n}=105,95 \%$ CI 0.65 to 1.15 ).

\section{DISCUSSION}

The total number of medications decreased from 2346 in 2014 to 2123 in 2018. Possible reasons could be the increased awareness of the side effects of medication abuse, the introduction of the new online reporting tool, teams taking part in 2018 that had not participated in previous tournaments and/or the occurrence of fewer injuries during the 2018 FIFA World Cup compared with past tournaments. In 2018, the injury rate per match during the tournament was 1.4 compared with 1.7 in the 2014 edition. Nevertheless, the intake of medication remained high, with $39 \%$ of players taking at least one medication prior to a match (see table 1$)$. The high intake of medication, in particular NSAIDs, is also seen in other competitions and sports. A systematic review found that in nearly all studies analysed, NSAIDs were the most used medication. ${ }^{11}$

In the 2018 FIFA World Cup, the average number of medications taken per match decreased for NSAIDs $(-20 \%)$ and injections $(-75 \%)$, but increased for analgesics $(+76 \%)$, antihistamines $(+36 \%), \beta-2$ agonists $(+5 \%)$ and supplements $(+94 \%)$ compared with the 2014 edition (see figure 1). ${ }^{10}$ The decrease in the use of NSAIDs is in line with the findings seen during the last FIFA World Cup, but it remains high, with one in four players being prescribed NSAIDs prior to a game. ${ }^{10}$ The team doctors prescribed 2.8 times more NSAIDs than other analgesics during the tournament. Compared to the 2014 FIFA World Cup, the intake of NSAIDs decreased while that of other analgesics increased, as did muscle relaxants (from $2.4 \%$ in 2014 to $6.7 \%$ in 2018). In 2017, an International Olympic Committee Consensus Group published guiding principles for the pharmacological management of pain. The guidelines stated, among other things, that only one medication for pain management should be prescribed at the time and that it should be combined with non-pharmacological measures. Furthermore, the lowest effective dose should be prescribed for the shortest period of time, and pain medication should not be given for injury or pain prevention. ${ }^{12}$ The percentages show that team doctors gave more analgesics and fewer NSAIDs compared with the previous World Cup in 2014. ${ }^{10}$ In absolute numbers, however, the intake of NSAIDs was still high. Another reason for the high increase in analgesics was that for one team, the team doctor prescribed paracetamol to every player before every match towards the end of the tournament, regardless of whether the player was in the starting line-up or was a substitute. The high intake of NSAIDs and analgesics across most teams could be due to the high physical demands of the sport, the short recovery phase between games and the long season that the players had had with their clubs. 


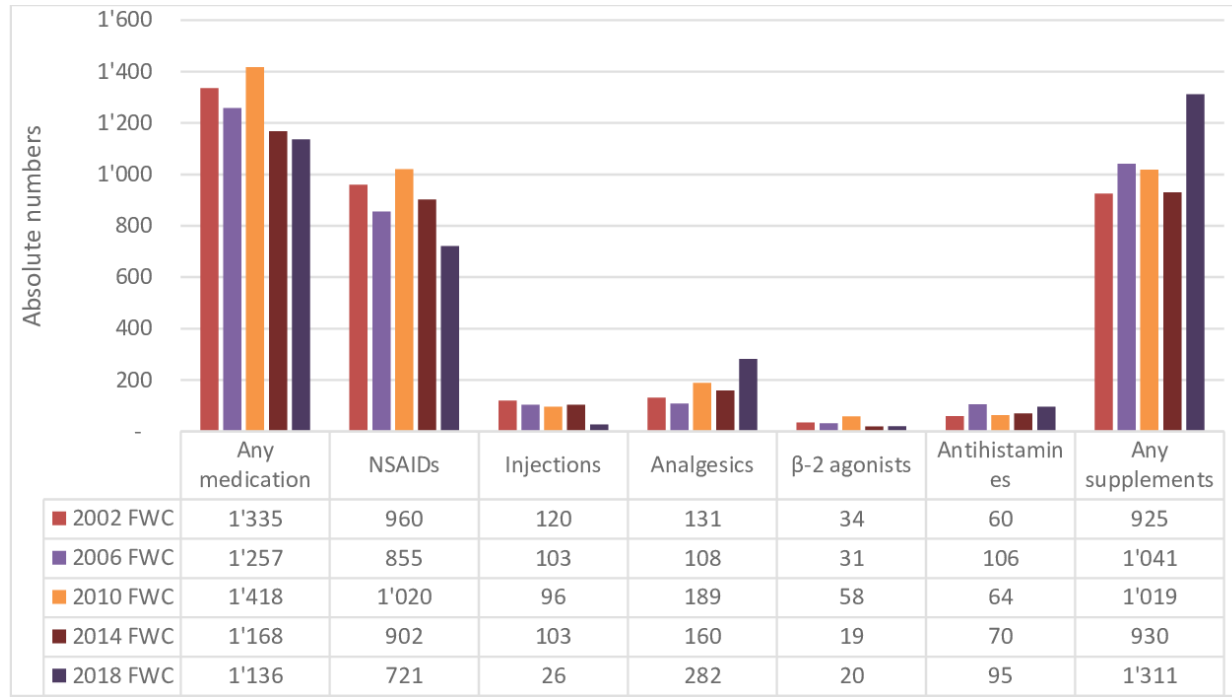

Figure 1 Comparison of substances used per match and per player at FIFA World Cups from 2002 to 2018. NSAID, nonsteroidal anti-inflammatory drug.

As previously reported in other studies, the high consumption of anti-inflammatory drugs is also present in other sports to increase pain tolerance, to reduce inflammation or pain, and to continue training and competing with minor injuries. ${ }^{13}{ }^{14}$ It has been reported that athletes from all levels and ages use pain-relieving medication up to four times more than the age-matched population. ${ }^{6}$ This finding demonstrates that there are gaps in the knowledge of the dose and administration of analgesics, in particular for the management of smaller injuries and bruises, and the treatment of pain during games. ${ }^{15}$ However, research has demonstrated that a high consumption of NSAIDs during exercise can lead to gastrointestinal events, changes in renal function and a negative effect on bone turnover. ${ }^{16-19}$

It has previously been reported that antiasthmatic medication is rarely taken by football players. ${ }^{20}{ }^{21}$ Asthma seems to be more prevalent in winter sports and sports such as swimming due to the inhalation of cold air or the ambient air of indoor swimming pools, which can lead to the development of exercise-induced airway inflammation or epithelial damage. ${ }^{22}$ In this edition of the World Cup, 16 players took antiasthmatic medication $(2.17 \%$ : six took montelukast, five inhaled corticosteroids and five inhaled salbutamol). According to the Prohibited List of the World Anti-Doping Agency (WADA) (as in January 2019), all $\beta-2$ agonists are prohibited. An exception, however, is 'inhaled salbutamol up to a maximum of 1600 micrograms over 24 hours in divided doses not to exceed 800 micrograms over 12 hours starting from any dose'. ${ }^{23}$ The reported numbers for antiasthmatic medications are similar to those for other World Cups. ${ }^{21}$

The team doctors reported an intake of 277 drugs against insomnia and anxiety compared with 142 in the 2014 FIFA World Cup. The intake of this category of medication for European teams increased from 32 to 124 compared with the intake from 4 years ago. ${ }^{10}$ This is surprising as there was less need to acclimatise in Russia due to the time difference than 4 years previously in Brazil. A reason for the increase could be the new online reporting tool and/or the more accurate reporting by the medical staff.

The findings after the 2010 and 2014 FIFA World Cups that more medications and NSAIDs were taken during the knockout stage compared with the group stage were confirmed with the present study. Explanations could be the increased demands as the tournament progresses or the accumulation of minor injuries during the season.

The South American teams took fewer medications per match and during the entire tournament in 2018 compared with $2014 .^{10}$ One reason could be that only five teams from South America qualified for the tournament in 2018, compared with six in 2014. Furthermore, the South American teams tended to exit earlier from the tournament, and the tendency shown is that teams take more medication per match in the knockout stage compared with the group stage. The differences between continents can be many, such as the seriousness with which the team doctor takes the online reporting tool or cultural differences in the use of medication. A study compared the self-medication of track and field athletes around the world and found that African and Asian athletes took significantly fewer medications than those from other continents. ${ }^{2}$ However, in the present study, the African countries took the fewest medications, as was also the case 4 years previously, although the intake of medication increased per match for the Asian countries. ${ }^{10}$ Nevertheless, it seems that continental differences are less important in football than in other sports, as often, players perform during the season in a country different from that of their national team and rely on the club doctor for their medication. ${ }^{4}$ Therefore, it is difficult to find meaningful results that distinguish between the different countries and cultures.

The trend found during the 2014 FIFA World Cup that older players take more medication than younger players 
was confirmed in this study. The players born before September 1990 took significantly more medication than those born after that month. They were also prescribed significantly more NSAIDs. Possible reasons could be that older players need more time to recover and be able to play at a high intensity compared with younger players and therefore try to speed up the recovery process with medication. However, further studies are needed in order to confirm this trend and to find appropriate explanations for it. It might also be that younger players are confronted at a younger age with the side effects that a high medication intake can produce.

The intake of supplements was investigated with the new online reporting tool. There are different reasons why athletes take supplements, including to prevent nutritional deficiencies that could impair performance, to accelerate recovery, to optimise body composition and for financial gain (sponsorship). ${ }^{24}$ In the 2018 edition of the FIFA World Cup, an increase in supplement intake was noticed from 930 to 1311 . This increase could be due to the introduction of the online reporting tool for medication and supplement intake or the fact that players do not always report all supplements they are taking to the team doctor. Players should be aware of the possible adverse effects of the use of supplements, including the issue of purity, as they might contain substances that are on the Prohibited List of WADA. ${ }^{25}{ }^{26}$ Players can fail a doping test without having intentionally taken the prohibited substance and can be suspended from playing. Therefore, they should take it on themselves to assess whether the benefits of taking the supplement outweigh the risk of inadvertently taking a contaminated substance. ${ }^{24}$ No positive doping results were found in this study population, showing that elite players were well instructed and advised by their team doctors.

\section{Limitations}

The accuracy of the data is dependent on the information received from team doctors. Furthermore, some players might not report all drugs and supplements to their national team doctors. Another limitation is that the dose and method of administration used were not taken into account.

\section{CONCLUSION}

The use of medication during the 2018 FIFA World Cup remained high. The total number of medications decreased slightly, but the amount of supplements increased compared with that of the 2014 edition. In particular, the intake of analgesics and NSAIDs remained high. There seems to be a need to increase the awareness of players, medical staff and coaches of the negative side effects of a high intake of analgesics and NSAIDs.

\section{Patient and public involvement statement}

The research was done without involvement of the athletes. They were not invited to comment on the study design, were not consulted to interpret the results and did not contribute to the writing or editing of this document.

Acknowledgements The authors thank FIFA for funding this study, as well as all of the team doctors for their cooperation (A. Martínez, M. Jones, K. Van Crombrugge, R. Lasmar, C. Ulloa, A. Ramirez, Z. Bahtijarevic, T. Krogh, M. Abouelela, R. Chakraverty, F. Le Gall, T. Meyer, H. Bjornsson, P. Khanlari, H. Ikeda, S. Lee, J. Serrano, A. Hefti, I. Gyaran, G. Martinez, J. Segura, J. Jaroszewski, P. Beckert, E. Bezuglov, D. Benkhelifa, A. Fediore, M. Mladenović, 0. Celada, J. Cota, A. Valentin, C. Wetzel, S. Chemli and E. Belza). The authors also express their gratitude to the members of the FIFA Medical Committee: chairman M. D'Hooghe, G. Singh, H. Ahmed, G. Chiampas, M. Forssblad, M. Fulcher, H. Herrero, G. Martínez, M. Dohi, D. Villani and Y. Zerguini. The authors would also like to thank the FIFA translation team, in particular, A. Hurley for his language editing and proofreading of this report.

Contributors All authors were involved in the study design and in the draft of this report.

Funding FIFA - MV, AW and $\mathrm{CO}$ were all funded by FIFA.

Competing interests None declared.

Patient consent for publication Not required.

Ethics approval The protocol was approved by the Ethics Committee of Zurich, Switzerland (Kantonale Ethikkommission). Informed consent was obtained in writing.

Provenance and peer review Not commissioned; externally peer reviewed.

Data availability statement All data relevant to the study are included in the article or uploaded as supplementary information.

Open access This is an open access article distributed in accordance with the Creative Commons Attribution Non Commercial (CC BY-NC 4.0) license, which permits others to distribute, remix, adapt, build upon this work non-commercially, and license their derivative works on different terms, provided the original work is properly cited, appropriate credit is given, any changes made indicated, and the use is non-commercial. See: http://creativecommons.org/licenses/by-nc/4.0/.

\section{REFERENCES}

1. Brune K, Niederweis U, Krämer B. Sport und Schmerzmittel: Unheilige Allianz zum Schaden der Niere. Deutsches Ärzteblatt 2008;105:1894-900.

2. Tscholl P, Alonso JM, Dollé G, et al. The use of drugs and nutritional supplements in top level track and field athletes. Am J Sports Med 2010;38:133-40.

3. Tscholl P, Feddermann N, Junge A, et al. The use and abuse of painkillers in international soccer: data from 6 FIFA tournaments for female and youth players. Am J Sports Med 2009;37:260-5.

4. Tscholl PM, Dvořák J. Abuse of medication during international football competition in 2010 - lesson not learned: table 1. Br J Sports Med 2012;46:1140-1.

5. Taioli E. Use of permitted drugs in Italian professional soccer players. Br J Sports Med 2007;41:439-41.

6. Alaranta A, Alaranta H, Heliövaara M, et al. Ample use of physicianprescribed medications in Finnish elite athletes. Int J Sports Med 2006;27:919-25.

7. Da Silva ER, De Rose EH, Ribeiro JP, et al. Non-steroidal antiinflammatory use in the XV Pan-American Games (2007). Br J Sports Med 2011;45:91-4.

8. Alaranta A, Alaranta $\mathrm{H}$, Helenius I. Use of prescription drugs in athletes. Sports Medicine 2008;38:449-63.

9. Suzic Lazic J, Dikic N, Radivojevic N, et al. Dietary supplements and medications in elite sport - polypharmacy or real need? Scand $J$ Med Sci Sports 2011;21:260-7.

10. Vaso M, Weber A, Tscholl PM, et al. Use and abuse of medication during 2014 FIFA World Cup Brazil: a retrospective survey. BMJ Open 2015;5:e007608.

11. Harle CA, Danielson EC, Smith L, et al. Analgesic management of pain in elite athletes: a systematic review. Clin J Sport Med 2018;28:417-26.

12. Hainline B, Derman W, Vernec A, et al. Internation Olympic Committee consensus statement on pain management in elite athletes. Br J Sports Med 2017;51:1245-58.

13. Gorski T, Cadore EL, Pinto SS, et al. Use of NSAIDs in triathletes: prevalence, level of awareness and reasons for use. Br J Sports Med 2011;45:85-90. 
14. Lundberg TR, Howatson G, et al. Analgesic and anti-inflammatory drugs in sports: implications for exercise performance and training adaptations. Scand J Med Sci Sports 2018;28:2252-62.

15. Zideman DA, Derman W, Hainline B, et al. Management of pain in elite athletes: identified gaps in knowledge and future research directions. Clin J Sport Med 2018;28:485-9.

16. Irving RA, Noakes TD, Raine RI, et al. Transient oliguria with renal tubular dysfunction after a $90 \mathrm{Km}$ running race. Med Sci Sports Exerc 1990;22:756-61.

17. Walker RJ, Fawcett JP, Flannery EM, et al. Indomethacin potentiates exercise-induced reduction in renal hemodynamics in athletes. Med Sci Sports Exerc 1994;26:1302-6.

18. Wheeler P, Batt ME. Do non-steroidal anti-inflammatory drugs adversely affect stress fracture healing? A short review. $\mathrm{Br} J$ Sports Med 2005;39:65-9.

19. Bailey Su J, O'Connor P. Nsaid therapy effects on healing of bone, tendon and the enthesis. J Appl Phys 2013;115:892-9.

20. Corrigan B, Kazlauskas R. Medication use in athletes selected for doping control at the Sydney Olympics (2000). Clin J Sport Med 2003;13:33-40.
21. Tscholl P, Junge A, Dvořák J. The use of medication and nutritional supplements during FIFA World Cups 2002 and 2006. Br J Sports Med 2008;42:725-30.

22. Carlsen KH, Anderson SD, Bjermer L, et al. Exercise-induced asthma, respiratory and allergic disorders in elite athletes: epidemiology, mechanisms and diagnosis: Part I of the report from the Joint Task Force of the European Respiratory Society (ERS) and the European Academy of Allergy and Clinical Immunology (EAACI) in cooperation with GA2LEN ${ }^{2}$ LEN. Allergy 2008;63:387-403.

23. World Anti-Doping Agency. Prohibited list, 2018. Available: https:// www.wada-ama.org/sites/default/files/prohibited_list_2018_en.pdf [Accessed 28 Feb 2019].

24. Maughan RJ, Burke LM, Dvořák J, et al. IOC consensus statement: dietary supplements and the high-performance athlete. $\mathrm{Br} J$ Sports Med 2018;52:439-55.

25. Judkins C, Prock P. Supplements and inadvertent doping - how big is the risk to athletes. Med Sport Sci 2012;59:143-52.

26. Maughan RJ, Shirreffs SM, Vernec A, et al. Making decisions about supplement use. Int J Sport Nutr Exerc Metab 2018;28:212-9. 